Olawale, B.E. et al. COVID-19 induced psychosocial challenges in South African higher education: Experiences of staff and students at two rural universities

\title{
COVID-19 induced psychosocial challenges in South African higher education: Experiences of staff and students at two rural universities
} \author{
Omodan $^{2}$ \\ *Corresponding Author: bolawale@ufh.ac.za \\ 1. Faculty of Education, University of Fort Hare, South Africa \\ 2. Faculty of Education, Walter Sisulu University, South Africa \\ Received : 2021-06-15 \\ Revised : 2021-08-11 \\ Accepted : 2021-09-28
}

Babawande Emmanuel Olawale ${ }^{1}$, Bonginkosi Hardy Mutongoza ${ }^{1}$, Emmanuel Olusola Adu ${ }^{1}$ \& Bunmi Isaiah

$10.46303 /$ ressat.2021.37

How to cite this paper: Olawale, B.E., Mutongoza, B.H., Adu, E. O. \& Omodan, B.I. (2021). COVID-19 induced psychosocial challenges in South African higher education: Experiences of staff and students at two rural universities. Research in Social Sciences and Technology, 6(3), 179193. https://doi.org/10.46303/ressat.2021.37

This is an Open Access article distributed under the terms of the Creative Commons Attribution 4.0 International license (https://creativecommons.org/licenses/by/4.0/).

\begin{abstract}
Although the global impact of the COVID-19 pandemic on the education and mental health of the university environment is relatively unknown, it is expected to be very significant considering the high incidence of emotional reactions amongst university students and staff. While fears around COVID-19 exposure, anxieties, and the challenges of support normalize stress, anxiety, and depression as emotional reactions in the face of the pandemic, this psychosocial impact has negative consequences for the university community. Thus, in order to salvage the higher education institutions from the debilitating effects of the pandemic, there is a clear need to safeguard the welfare of students and staff. Hence, it becomes vital to examine the experience of members of the university community during the COVID-19 crisis in order to develop measures and implement interventions that will assist in navigating psychosocial challenges. Underpinned by Hettler's model of holistic wellness which was developed to promote wellness in the university community settings, the study employed a mixed-method research approach in which data was collected using web-based survey and online interviews. Concurrent triangulation sampling technique was employed to select a sample of fifteen students, five university managers, and five lecturers - making twenty-five respondents at each of the two universities, thus making a cumulative total of fifty at two rural universities in the Eastern Cape Province, South Africa. Thus, quantitative and qualitative data collected were analysed concurrently by first reporting the quantitative findings and then comparing them with qualitative findings. Findings revealed that although the university environment traditionally provided opportunities for strengthening social ties which satisfy the universal need to belong to a community, the COVID-19 pandemic has altered rural university life, thus, significantly impacting on psychosocial wellbeing. The study recommends that rural institutions must facilitate psychosocial wellness programming with the assistance of wider stakeholders such as the government and the private sector who can assist in financing this initiative.
\end{abstract}


Olawale, B.E. et al. COVID-19 induced psychosocial challenges in South African higher education: Experiences of staff and students at two rural universities

Keywords: COVID-19; challenges; emotional reaction; impact; pandemic; psychosocial

\section{Introduction}

The COVID-19 pandemic has disrupted all aspects of society in ways that nobody could have imagined. As a measure to curtail the spread of the highly infectious virus, countries set in place various strategies to limit the movement of people (and the resultant transmission of the virus). Such strategies include the enactment of lockdowns, the banning of public gatherings, wearing of masks, sanitizing of hands, etc. (McCorkle, 2020; Sahu, 2020). These measures meant that education institutions (schools, colleges, universities, etc.) were closed and alternative methods of instruction had to be formulated (Adeyon \& Soykan, 2020; Ebrahim et al., 2020). This gave rise to the establishment of online learning in order to rescue education, albeit with very minimal preparedness especially in rural settings where the infrastructure to enable online learning was barely existent (Dube, 2020; Mncube al., 2021). Remote learning however presents various challenges for students and staff at higher education institutions - for example the lack of access, training and unavailability of online resources (Dhawan, 2020; Kalimullina et al., 2021; Muhuro \& Kang'ethe, 2021), complications of assessment and evaluation (Ntshwarang et al., 2021; UNESCO, 2020).

The COVID-19 pandemic has also had a profound effect on mental health, owing to the strains and pressures created by the abrupt change in the way of life (Liu et al., 2020). The pandemic has created an unparalleled amount of stress on university communities because of the anxiety, uncertainty of the future, pressures associated with learning from home, challenges associated with time management, etc. (Budiharso \& Tarman, 2020; Cao et al., 2020; Hasan \& Bao, 2020; Tang et al., 2020). In fact, the incidence of stress, anxiety, and depression seem to be increasing in most organisations, despite intensified scientific attention to this phenomenon from various disciplines. This is exacerbated with the complexities which the pandemic has brought to the fore, wherein academics who initially were involved in offering moral support to students' needs, incessantly grapple with tasks other than their core teaching functions in order to maintain the functionality of institutions (Mncube et al., 2021; Williams et al., 2021).

In South African universities, psychosocial wellness has recently become embedded in the pressing public health issues owing to unprecedented incidents of attempted suicide and suicide occurrence in the country (Makhubela, 2021; van Zyl et al., 2017). These concerns are more pronounced in rural universities which in most instances have very limited resources for students and staff to cope amid the academic pressures extant in universities (Pillay et al., 2020; Rousseau et al., 2021). Psychosocial challenges significantly impede social adjustment to university and academic attainment and is linked to increased suicidality (Laher et al., 2021). It is contended that university communities are shown to be at a higher risk particularly around times of transition, and psychosocial wellness is shown to decrease significantly around times of major transitions at universities (Cvetkovski et al. 2019; Poalses \& Bezuidenhout, 2018).

The abrupt transition into online learning in order to cope with the pandemic resulted in a loss of the social aspects of university life and this resulted in common anxieties and fears which significantly affect the psychosocial wellness of students and staff (Laher et al., 2021). Protocols instituted to curb the spread of the pandemic have also been large ones that dissuade social cohesion, thus while students and staff in developed contexts may have access to technologies 
Olawale, B.E. et al. COVID-19 induced psychosocial challenges in South African higher education: Experiences of staff and students at two rural universities

which can bridge the social vacuum, their rural counterparts are usually priced out of such technologies and alternative strategies of doing community (Hasan \& Bao, 2020; Rajkumar, 2020). As such, this study sought to examine the psychosocial challenges experienced by students and staff at two rural universities amid the COVID-19 pandemic.

\section{Literature Review: Impacts of COVID-19 and the risk factors of its psychological impacts}

For the general public, while some were overconcerned about the lockdown-related scarcity of emergency and essential services, the unrealistic panic led to false feelings created a detrimental impact on the community that genuinely requires these essentials and promote unconcealed black market which led to social injustice and activity disruptions (Mahase, 2020). As evident in the previous contagious disease outbreaks such as the 2003 Severe Acute Respiratory Syndrome (SARS), it is not uncommon for patients, perceived patients, and/or health workers, to suffer stigmatization (Siu, 2008; Verma et al., 2004). In the same vein, the outbreak of the COVID-19 pandemic has given rise to stigmatization factors such as fear of isolation, discrimination, racism and marginalization with all its economic and social implications (Dubey et al., 2020). According to Dubey, et al. (2020), a stigmatized set of people or society may find it difficult to seek medical attention, as well as hide medical history, specifically of travel. This attitude in turn is capable of increasing community transmission risks. As such, the World Health Organisation issued a detailed psychosocial consideration for lessening the growing stigma of the COVID-19 pandemic (World Health Organization, 2020).

While the psychological impact of COVID-19 amongst children, old age, domestic caregivers, as well as the general public is being overlooked (Dubey et al., 2020), developmental psychologist largely found that learned experiences through environmental factors among children during early childhood provide a solid background for lifetime behaviour and success given that it is a fundamental phase for emotional, cognitive, as well as the psychosocial skill development (Dubey et al., 2020; Ghosh et al., 2020; Wang et al., 2020). Thus, community-based mitigation programmes such as closing of schools, playgrounds, as well as amusement parks, disrupt children's normal lifestyle which can potentially cause distress and confusion (Dubey et al., 2020). Similarly, documented psychological impact of the COVID-19 on higher education students revealed that most students feel increased stress level, anxiety, and depression as a result of changed delivery and uncertainty of university education, social isolation, decrease family income as well as the fear of future employment (Aristovnik et al., 2020).

Thus, while previous studies have discussed an intense and wide spectrum of psychosocial ramification that the COVID-19 pandemic can inflict on the general public, the fear of "coronaphobia" (Asmundson \& Taylor, 2020) is caused as a result of uncertain characters and unpredictable course of the disease, perceived risk of acquiring the infection, as well as the intolerance of uncertainty among many others (Dubey et al., 2020). These can therefore generate negative psychological responses which include maladaptive behaviour, avoidance reaction among common people and emotional distress (Taha et al., 2014). Similarly, while people bereaved from the death of colleagues, dear friends, as well as their beloved ones due to COVID-19 pandemic, their inability to gain closure, bury and/or cremate their loved ones can as well result in frustrations, resentment, anger, psychological trauma and long-term psychiatric sequelae (Dubey et al., 2020; Ho et al., 2020). 
Olawale, B.E. et al. COVID-19 induced psychosocial challenges in South African higher education: Experiences of staff and students at two rural universities

In coping with the challenges caused by COVID-19 pandemic, university members may exhibit several unpleasant behaviours such as impatience, annoyance and hostility. Such behaviours may in turn cause them to suffer from physical and mental violence caused by overly pressurized parents, disappointment, lack of face-to-face contact with classmates, friends and educators, lack of enough personal space at home, among many others which can potentially trigger troublesome and even prolonged adverse mental consequences (Wang et al., 2020). Thus, while remote classes, online assignments as well as assessment have been the most effective way of salvaging the education sector, various researchers have warned against the stress it brings (Dubey et al., 2020).

Thus, Shimazu et al. (2020) highlighted a few immediate strategies that could assist in protecting mental health from psychosocial (such as sleep and healthy nutrition); psychological (such as coping and relaxation); behavioural (physical activities); and social (e.g. communication) aspects. In addition, Holmes et al. (2020) argue for a longer-term strategy that could be considered in promoting psychosocial wellbeing which include the positive mechanistic-based component such as problem-focused approach which helps maintain control over situations and the creation of positive events in daily life that provide momentary respite from chronic stress (Shimazu et al., 2020).

\section{Theoretical Framework}

The current study is underpinned by Hettler's (1984) model of holistic wellness which was developed to promote wellness in the university community settings.

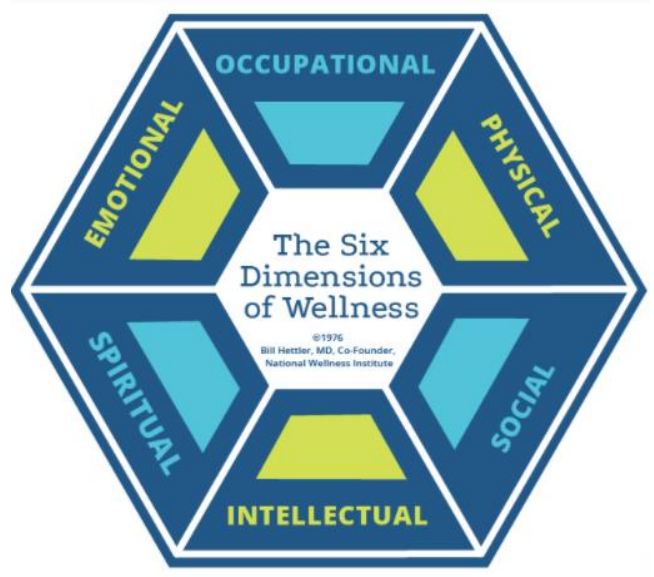

Figure 1. Hettler's (1984) model of holistic wellness

According to Hettler (1984), holistic wellness is made up of six broad dimensions of healthrelated behaviours namely: physical wellness, emotional wellness, spiritual wellness, social wellness, occupational wellness, and intellectual wellness. For Hettler (1984), a person who strives for holistic wellness is aware of all aspects of wellness and consciously works to incorporate these elements into one's daily life. In other words, the pursuit of wellness is a lifelong endeavour, and educational facilities are ideal settings for wellness promotion (Harrington, 2016; Miller et al., 2008). As such, this model is useful for this study because it emphasises that people who are aware of the interconnectedness of each of the dimensions of the holistic wellness model will contribute to a healthy university community. This is because 
Olawale, B.E. et al. COVID-19 induced psychosocial challenges in South African higher education: Experiences of staff and students at two rural universities

the model explains the different aspects of psychosocial wellness - arguing how such wellness can contribute to the development of better living spaces and social networks.

\section{Problem statement}

While the impact of the COVID-19 pandemic is felt across all populations, most especially communities that are socially disadvantaged, as well as individual who are employed as social workers, research shows that students and staff in the higher institute of learning are amongst the most who are strongly affected by the pandemic (Aristovnik et al., 2020; Dubey et al., 2020). This is because of uncertainty regarding academic success, social life, as well as future careers (Aristovnik et al., 2020; Lima et al., 2020; Rajkumar, 2020). Thus, given that prior to the pandemic outbreak, university communities across the globe continue to experience an increased level of depression, lack of self-esteem, anxiety, violence, abuse of substances, as well as suicidality (Holm-Hadulla \& Koutsoukou-Argyraki, 2015; Rajkumar, 2020), the fears around COVID-19 exposure and many challenges faced by university students contributed to pre-existing stressors which thus have a negative consequence for the university community. Therefore, to salvage the higher education institutions (HEIs) from the debilitating effects of the pandemic, there is a clear need to safeguard the welfare of students and staffs by investigating COVID-19-induced psychosocial challenges in order to establish relevant approaches to deal with the physical and mental health repercussion of the pandemic.

\section{Research questions}

In order to elicit the experiences of students and staff with regards to COVID-19-induced psychosocial challenges in South African higher education, this study sought to answer the following questions:

- How has the COVID-19 pandemic affected workloads and productivity in universities?

- How has the COVID-19 pandemic affected interpersonal relationships in universities?

\section{Methodology}

\section{Research paradigm}

This study was underpinned by the post-positivism paradigm because it enables the researchers to get a broad insight and an in-depth picture on the experiences of students and staffs with regards to COVID-19-indcued psychosocial challenges in South African higher education.

\section{Research approach}

To get a better knowledge of the phenomena under investigation, a mixed method approach was used. A mixed methods approach is one that combines quantitative and qualitative research methodologies (Creswell \& Creswell, 2018). This approach allowed the researchers to accumulate in-depth information on the experiences of students and staffs with regards to COVID-19 induced psychosocial challenges in South African higher education. 
Olawale, B.E. et al. COVID-19 induced psychosocial challenges in South African higher education: Experiences of staff and students at two rural universities

\section{Research design}

Based on the use of mixed method research approach, the study was informed by a concurrent triangulation design whereby the researchers used quantitative and qualitative methods simultaneously to best understand the phenomenon under investigation (Leavy, 2017).

\section{Population, sample and sampling techniques}

The population of the study was composed of staff and students at two rural universities in South Africa from which participants for the study were selected. In collecting data, we employed a concurrent triangulation sampling technique to select participants for this study. A sample of fifteen (15) students, five (5) university managers, and five (5) lecturers - making twenty-five (25) respondents at each of the two universities, thus making a cumulative total of fifty $(50)$ respondents who participated in both phases of the study.

\section{Data collection instruments}

Because mixed methods data collecting entails employing different tactics, techniques, and ways of requesting information from respondents, both quantitative and qualitative data gathering methods were employed (Creswell \& Creswell, 2018). In the qualitative phase, data were collected using semi-structured online interviews with the students and staff, while quantitative data were collected using a web-based survey which was distributed to students and staff who had participated in the qualitative phase. As such, the researchers only used data from participants who participated in both phases of the study.

\section{Data analysis}

The quantitative data were analysed descriptively - we provided simple summaries about the sample and findings, while the qualitative data were analysed thematically - we summarised and organised the data based on emerging themes from interviews. Thus, quantitative findings were presented first and then compared to the qualitative findings.

\section{Results and Discussion}

The study sought to investigate the experiences of staff and students at two rural universities with regards to COVID-19-induced psychosocial challenges in South African higher education. As such, research findings were presented and discussed under the following sub-headings:

- Workload management and productivity-related challenges

- Interpersonal relationships-related challenges

\section{Workload Management and Productivity}

Research findings from the quantitative phase of the study in Figure 2 below shows the COVID19-related psychosocial challenges faced by the university community with regards to workload management and productivity. 
Olawale, B.E. et al. COVID-19 induced psychosocial challenges in South African higher education: Experiences of staff and students at two rural universities

\section{Workload managament and Productivity}

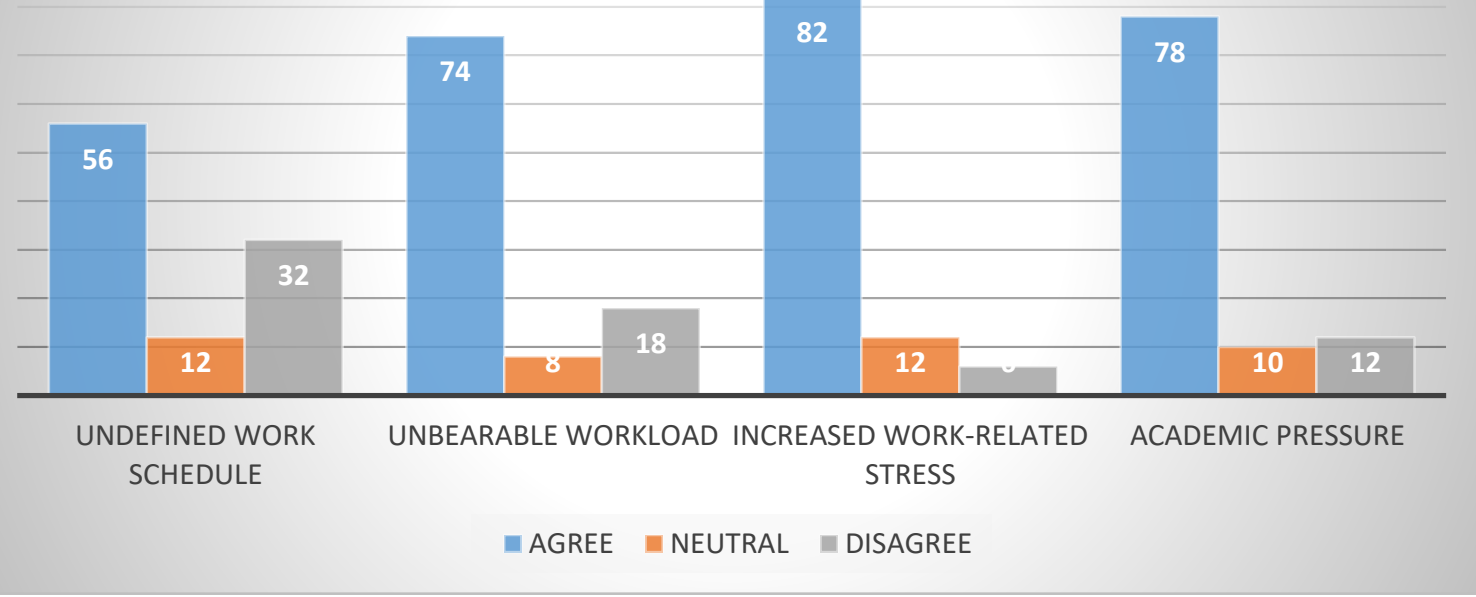

Figure 2. Workload management and productivity

Data revealed that $56 \%$ of the participants in both universities indicated that one of the major challenges that affected their psychosocial wellness in the domain of workload management and productivity was an undefined work schedule, while $32 \%$ of the participants disagreed and $12 \%$ remained neutral. This implies that since the abrupt transition to online learning caused by the COVID-19 pandemic, institutions are struggling to define work schedules that boost productivity. Research findings also revealed that $74 \%$ of the participants lamented about the unbearable workload which they have to deal with, while $18 \%$ of the participants seemed not to have a problem with the workload, and $8 \%$ remained neutral. As such, it is evident from the participants' response that the unbearable workload led to an increased work-related stress as $82 \%$ of the participants noted an increase in such stresses, while $6 \%$ disagreed and $12 \%$ remained neutral. The data also revealed that students and staff are struggling to grapple with increased academic pressure owing to the initial COVID-19-induced temporary closure of higher education institutions. To this end, $78 \%$ of the participants noted that academic pressure was a significant challenge impacting their psychosocial wellness, while $10 \%$ of the students remained neutral, and a meagre $12 \%$ disagreed.

In the qualitative phase, in order to elicit the COVID-19-related psychosocial challenges faced by the members of the university community, participants were asked "how has the COVID-19 pandemic affected workloads and productivity?" Research findings revealed that as institutions are rebuilding education practices which have been affected by the COVID-19 pandemic students and staff had challenges with regards to time management, work-overloads, undefined work schedules, as well as poor workload planning which directly impacted on work productivity. A case in point can be seen in the response of a lecturer at University B who bemoaned:

The pandemic has heavily affected me at several levels, for example, I do not have enough time for my academic work ever since the beginning of the pandemic, [...] we unexpectedly shifted to online teaching and learning with very little training and 
Olawale, B.E. et al. COVID-19 induced psychosocial challenges in South African higher education: Experiences of staff and students at two rural universities

resources. As such, having a clearly defined work schedule has become a huge problem. (Lecturer 4, University B)

A student at University A corroborated these sentiments arguing:

Since the reopening of our university, we are always trying to catch-up on schedules [...] it always seems like we are behind in terms of the academic programme. Sometimes I feel like lecturers are overloading us and not taking our situations into consideration, [...] it appears as though they only think that we are taking one module, [...] it is just overwhelming and depressing for students. (Student 13, University A)

In the same vein, a student also reiterated the challenges related to workloads and productivity by noting:

[...] I have been able to learn new things, for example the use of ICT in learning, it however appears as though the lecturers in my faculty do not put students into consideration in terms of workload planning because they are simply interested in the dishing out and submission of tasks for assessment. This comes as added pressure to the already challenging adoption of online learning which we did not know. (Student 7, University B)

A Manager also added:

You see, workloads are difficult to manage in the face of the pandemic. Both staffs and students are complaining about having too much work, but what can we do? The university has expectations, [...] students must be taught, and lecturers must teach and assess. It is a stressful time for both students and lecturers, [...] this has to be done using technologies which we all are still trying to learn because we never really did these online things before the pandemic. (Manager 3, University A)

The challenges related to workloads were also pronounced by a student:

I have failed to submit a couple of assignments because of the unbearable workloads. I come from rural areas where sometimes I struggled with connectivity and I would get some of the assignments late. Now in order to stay afloat, I have resorted to copying. If I don't copy, I fail, and if I fail, my funding will be withdrawn you see? Some of us do not have the luxury to fail, we simply cannot. They say desperate times need desperate measures. (Student 14, University A)

Research findings revealed that workload management in higher education institutions is affected by unclearly defined work schedules, unbearable workloads, increased work-related stress, academic pressure from taking and preparation for online assessments, as well as the pressure to acquire large amounts of knowledge in very limited timespans. The findings also revealed that students are confronted by performance-related challenges with regards to maintaining bursaries and funding for their studies. This was identified as adding significant stresses on the pursuit of studies, thus some students resorted to academic dishonesty in order to safeguard their bursaries and funding in the wake of the uncertainties induced by the pandemic. These findings corroborate that of Patterson et al. (2020) who argue that the COVID19 crisis possess a significant amount of workload increase to students and lecturers as they 
Olawale, B.E. et al. COVID-19 induced psychosocial challenges in South African higher education: Experiences of staff and students at two rural universities

strive to move towards the online teaching and learning model. This transition to an online pedagogy gave rise to increased workload burdens for the university community in their quest to ensure the continuity of academic activities. Staffs and students are therefore confronted by exhaustion, fatigue and financial constraints (Laher et al.,2021; Patterson et al., 2020). Similarly, Cao et al. (2020) add that the COVID-19 pandemic has created an unparalleled amount of stress on university communities because of the anxiety, uncertainty of the future, pressures associated with learning from home, challenges associated with time management, etc.

Thus, findings from both quantitative and qualitative study revealed that COVID-19-induced psychosocial challenges may have a considerable impact on productivity in higher education institutions. Such challenges include, undefined work schedule, unbearable workload, increased work-related stress, as well as academic pressure. These findings corroborate that of Aristovnik et al. (2020) who posit that the consequences of such challenges often result in increased stress level, anxiety, and depression as a result of changed delivery and uncertainty of university education, and social isolation. This is because according to the holistic model of wellness, wellness is made up of six inter-related dimensions which equally affect the psychosocial wellbeing of an individual in the university setting (Hettler, 1984). As such, research demonstrates that psychosocial challenges often result in increased absenteeism, lower job engagement and reduced performance from both students and staff (International Labour Organization, 2020).

\section{Interpersonal Relationship}

Findings from the quantitative phase of the study in Figure 3 below shows the COVID-19-related psychosocial challenges faced by the university community with regards to interpersonal relationships.

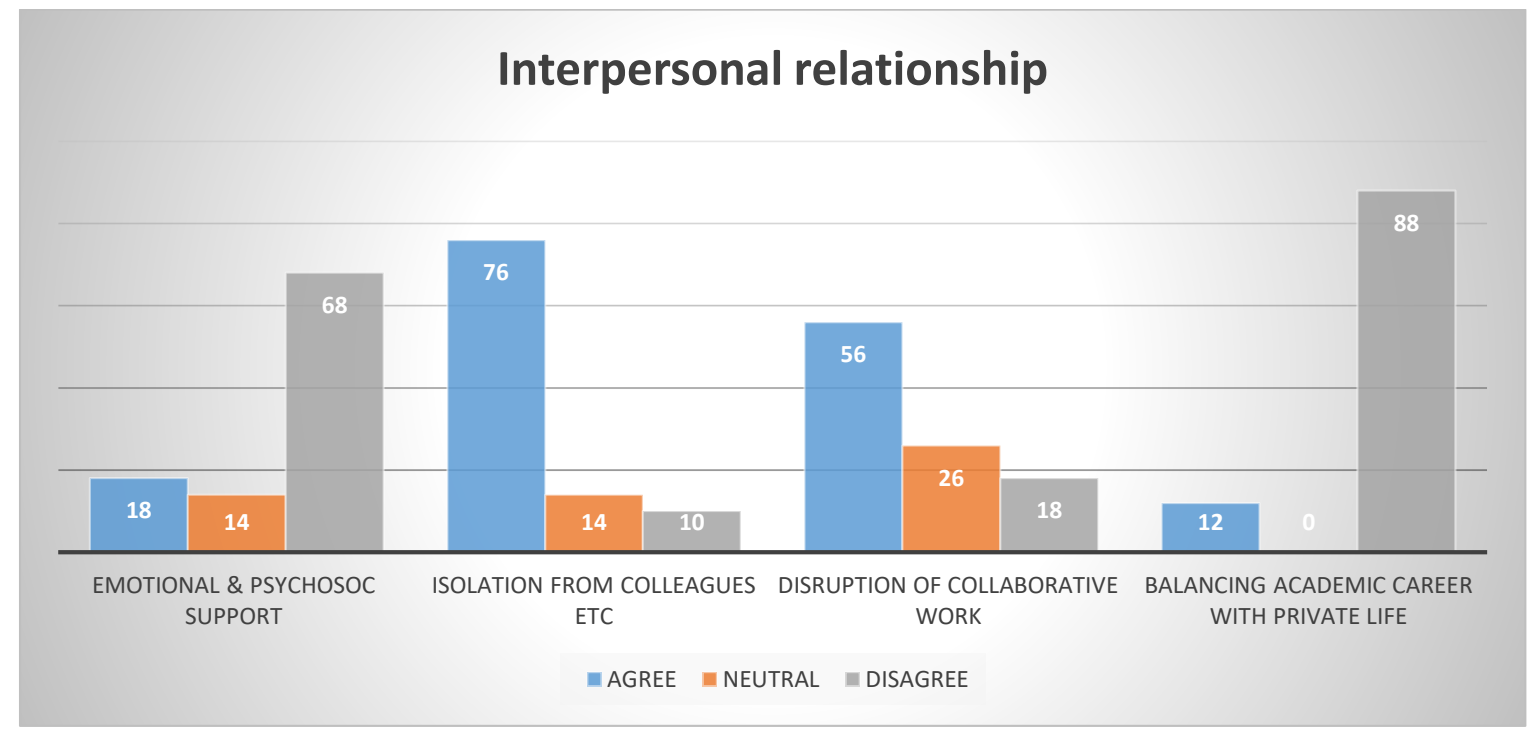

Figure 3. Interpersonal relationships

Data revealed that challenges that affected participants' psychosocial wellbeing with respect to interpersonal relationships were the lack of adequate support, as $68 \%$ of the participants indicated that there is lack of emotional and psychosocial support, while $14 \%$ remained neutral, 
Olawale, B.E. et al. COVID-19 induced psychosocial challenges in South African higher education: Experiences of staff and students at two rural universities

only $18 \%$ agreed that the institution provides such support. This implies that rural institutions do not have adequate psychosocial support for their students and staff. As such, these university community members are often left to fend for their own wellness. Research findings further revealed that while $10 \%$ of the participants disagreed that they felt lonely during selfisolation, and $14 \%$ remained neutral, the larger percent of the population (76\%) agreed that isolation or working from a separate space possess a lot of challenges which had a negative impact on their wellbeing. This becomes more acute when one considers the foregoing finding that most students and staff are without adequate support to cope with the stresses that come with the COVID-19 pandemic. Members of the university community are thus left without sufficient social capital to cope in the wake of COVID-19 stringencies. As a result, this led to work interruption as $56 \%$ of the participants indicated that disruption of collaborative work amongst peers are resultant of self-isolation, 26\% remained neutral, and $18 \%$ disagreed. However, while a minority of $12 \%$ of participants indicated that they were able to balance their academic careers with their private life, results indicated that $88 \%$ of the participant continue to find it very difficult to maintain this balance.

To gather qualitative information from participants on the psychosocial challenges faced by the members of the university community, participants were asked "how has the COVID-19 pandemic affected your interpersonal relationships?" Research findings revealed that the lack of emotional and psychosocial support, isolation, disruption of collaborative work, balancing academic career with work commitment are some of the major challenges affecting the university community's wellness in the wake of COVID-19 pandemic. For instance, a student at University B lamented:

I left the university when the first lockdown happened, and I was far away from my colleagues. We never really got an opportunity to bond as classmates since we were forced to close just as our semester was starting. Now we have returned to campus, but we cannot really interact freely with each other. You see, after a busy week of assignments and tests, we used to go out and refresh with my friends, but now we just cannot. Even in my romantic relationship, I am always on the edge, worrying and stressing about the possibility of getting the virus from my partner or giving it to him. The social distancing has separated us [...] we are lonely and isolated. University is where we must build lifelong friendships that we carry into adulthood, but this is difficult because those who live close to the university can go home regularly while some of us are left isolated in our rooms doing online learning. (Student 1, University B)

Similar sentiments were also revealed by lecturers who revealed how the pandemic has significantly changed their relationships around the university. A lecturer admitted:

Sometimes just being in the same vicinity with colleagues helps you to refresh. It gives you a sense that we are moving at a similar pace and in the same direction. This has changed because we are largely working apart [...] I am often haunted by the feeling that I am behind my colleagues in terms of coverage of course content. We seem to continually not have time for the small chit chats which we used to have before the pandemic. Everyone is always busy trying to catch-up. I do not feel like we are a team, we are just a collective of individuals. (Lecturer 2, University A) 
Olawale, B.E. et al. COVID-19 induced psychosocial challenges in South African higher education: Experiences of staff and students at two rural universities

The findings revealed that even managers from the university agreed that the COVID-19 pandemic has significantly caused psychosocial rifts, especially with regards to interpersonal relationships which are oftentimes used to cope with challenges. These sentiments are effectively captured in the views of a manager who posited:

We have had to relearn how to do life as members of the university community. Instead of merely sending out tasks and expecting reports from those you are delegating duties to, it is important to get a sense of the person behind the job being done. Sadly, we have not been able to work like we used to. Sometimes, I have to step in and work to do my part in keeping the institution going - even on weekends where my family expects me to spend time with them. It is literally everyone who is struggling. I think many families might come out of this pandemic broken because many people are failing to find the balance between earning a living and being involved in their families. (Manager 5, University B)

A student also added views on how the psychosocial challenges of COVID-19 are heavily interwoven into other aspects of student life. The student voiced:

This COVID thing is really difficult for relationships. It is emotionally and psychologically draining to live life while being in constant fear that I may get it. The need to stay safe then drives you away from your peers and friends because they tell us that we must stay apart to save lives [...] but these very people you are supposed to stay apart from are the very network that helps you to cope when you get stressed by academic work or anxious. I personally have suffered many mental breakdowns but there are very little support structures offered by the institution. You have to deal with all these things while battling to pass your modules [...] if you do not, then you lose funding. That is also an additional stress, my grandmother back home cannot finance my studies. How can a normal human being deal with all these things? (Student 12, University A)

Research findings revealed that interpersonal relationships in higher education institutions are affected by the COVID-19 pandemic owing to issues like limited psychosocial support, isolation, the disruption of collaborative work, etc. It is therefore not uncommon for students and staff to bemoan the psychosocial stresses as witnessed in references to being emotionally drained, lonely, and without adequate support services in the wake of the COVID-19 stringencies. The added pressure associated with transitioning into a relatively new form of learning (which had its own complications) which came against the backdrop of striving to maintain good grades and completion of course content, is also evidently increasing the likelihood of psychosocial pressures on the university community. These findings corroborate Laher et al. (2021) who note that psychosocial challenges significantly restrict social adjustment in higher education institutions, hinder academic attainment, and can be linked to increases in suicides when people fail to cope with such pressures. The unique setting of rural institutions puts such institutions at more significant risk because they usually do not have sufficient resources to help students cope (Pillay et al., 2020; Rousseau et al., 2021).

Findings from both quantitative and qualitative study revealed that COVID-19-induced psychosocial challenges have significant impact on interpersonal relationships. These challenges include isolation from peers, colleagues, as well as the university community, lack 
Olawale, B.E. et al. COVID-19 induced psychosocial challenges in South African higher education: Experiences of staff and students at two rural universities

of emotional and psychosocial support, and the inability to balance work in the academic domain with private life. This has significant implications for psychosocial wellness as presented in Hettler's (1984) wellness model which postulates that individuals within the university community must actively seek balance in the pursuit to enhance personal relationships and friendships. This pursuit, of relationships and balance has significantly been altered in the face of the pandemic as highlighted in the findings. This can be corroborated by Laher et al. (2020) who note how COVID-19 has had an extended impact on the loss of social aspects of university life. While the developed world has access to technologies which may help to bridge the social vacuum, poorer countries and institutions are usually priced out of these technologies, and their students and staff are left without no recourse (Hasan \& Bao, 2020; Rajkumar, 2020).

\section{Conclusion and Recommendation}

The degree to which an individual can balance life challenges successfully is a direct reflection of their level of psychosocial wellness. Our research findings highlight COVID-19-induced psychosocial challenges in South African higher education as well as aspects of wellness which are a source of concern for rural academic institutions. Although the university environment traditionally provided opportunities for strengthening social ties which satisfies the universal need to belong to a community, it is not surprising that COVID-19 pandemic altered rural university life, thus, significantly impacting on psychosocial wellbeing as isolation, lack of support, workload, etc. in the absences of resources, has produced feelings of stress and burnout. As such, the study recommend that rural institutions must facilitate psychosocial wellness programming with the assistance of wider stakeholders such as government and the private sector who can assist in financing this initiative. We also recommend that institutions must review their academic programmes and rid them of unnecessary stresses for students and staff based on their institution-specific settings. This would go a long way in ensuring the survival of rural institutions and their communities in the wake of both the current pandemic, and possible future disruptions which may occur to the learning project.

\section{References}

Adeyon, O. B., \& Soykan, E. (2020). COVID-19 pandemic and online learning: The challenges and opportunities. Interactive Learning Environments, 1-13. https://doi.org/10.1080/10494820.2020.1813180

Aristovnik, A., Keržič, D., Ravs`elj, D., Tomaž evič, N., \& Umek, L. (2020). Impacts of the COVID-19 pandemic on life of higher education students: A global perspective. Sustainability, 12(20), 8438. https://doi.org/10.3390/su12208438

Asmundson, G., \& Taylor, S. (2020). Coronaphobia: fear and the 2019-nCoV outbreak. Journal of Anxiety Disorder, 70, 1-12. https://doi.org/10.1016/j.janxdis.2020.102196

Budiharso, T. \& Tarman, B. (2020). Improving Quality Education through Better Working Conditions of Academic Institutes, Journal of Ethnic and Cultural Studies, 7(1), 99-115. http://dx.doi.org/10.29333/ejecs/306

Cao, Z., Fang, Z., Hou, G., Han, M., Xu, X., Dong, J., \& Zheng, J. (2020). The psychological impact of the COVID-19 pandemic on college students in China. Psychiatry Research, 278, 1-5. https://doi.org/10.1016/j.psychres.2020.112934 
Olawale, B.E. et al. COVID-19 induced psychosocial challenges in South African higher education: Experiences of staff and students at two rural universities

Creswell, J., \& Creswell, D. (2018). Research Design: Qualitative, Quantitative and Mixed Methods Approaches. Thousand Oaks: SAGE.

Cvetkovski, S., Jorm, A. F., \& Mackinnon, A. J. (2019). An analysis of the mental health trajectories of university students compared to their community peers using a national longitudinal survey. Studies in Higher Education, 44(1), 185-200. https://doi.org/10.1080/03075079.2017.1356281

Dhawan, S. (2020). Online learning: A panacea in the time of COVID-19 crisis. Journal of Educational Technology Systems, 49(1), 5-22. https://doi.org/10.1177/0047239520934018

Dube, B. (2020). Rural online learning in the context of COVID-19 in South Africa: Evoking an inclusive education approach. Multidisciplinary Journal of Educational Research, 135157. https://doi.org/10.17583/remie.2020.5607

Dubey, S., Biswas, P., Ghosh, R., Chatterjee, S., Dubey, M., Chatterjee, S., . . Lavie, C. (2020). Psychosocial impact of COVID-19. Diabetes \& Metabolic Syndrome: Clinical Research \& Reviews, 779-788. https://doi.org/10.1016/j.dsx.2020.05.035

Ebrahim, S. H., Ahmed, Q. A., Gozzer, E., Schlagenhauf, P., \& Memish, Z. A. (2020). COVID-19 and community mitigation strategies in a pandemic. The Business Management Journal, 368, m1066. https://doi.org/10.1136/bmj.m1066

Ghosh, R., Dubey, M., Chatterjee, S., \& Dubey, S. (2020). Impact of COVID-19 on children: special focus on psychosocial aspect. Minerva Pediatrica, 72(3), 226-235. https://doi.org/10.23736/S0026-4946.20.05887-9

Harrington, S. (2016). "America's healthiest campus": The OSU well-being strategy model. American Journal of Health Promotion, 30, 2-4.

Hasan, N., \& Bao, Y. (2020). Impact of "e-Learning crack-up" perception on psycological distress among college students during COVID-19 pandemic: A mediating role of "fear of academic year loss". Children and Youth Services Review, 118, 105355. https://doi.org/10.1016/j.childyouth.2020.105355

Hettler, B. (1984). Wellness: Encouraging a lifetime pursuit of excellence. Health Values, 8 , 13-17.

Ho, C. S., Chee, C., \& Ho, R. (2020). Mental health strategies to combat the psychological impact of COVID-19 beyond paranoia and panic. Annals of Academy of Medicine Singapore, 1-3. https://doi.org/10.47102/annals-acadmedsg.202043

Holmes, E., O'Connor, R., Perry, V., \& et.al. (2020). Multidisciplinary research priorities for the COVID-19 pandemic: a call for action for mental health science. Lancet Psychiatry, 113. https://doi.org/10.1016/S2215-0366(20)30168-1

Holm-Hadulla, R., \& Koutsoukou-Argyraki, A. (2015). Mental health of students in a globalized world: Prevalence of complaints and disorders, methods and effectivity of counselling, structure of mental health services for students. Mental Health \& Prevention. 3(1-2), 1-4. https://doi.org/10.1016/j.mhp.2015.04.003

International Labour Organization. (2020). Managing work-related psychosocial risks during the COVID-19 pandemic. Geneva: ILO Publications.

Kalimullina, O., Tarman, B. \& Stepanova, I. (2021). Education in the Context of Digitalization and Culture: Evolution of the Teacher's Role, Pre-pandemic Overview. Journal of Ethnic and Cultural Studies, 8(1), 226-238. DOI: http://dx.doi.org/10.29333/ejecs/629 
Olawale, B.E. et al. COVID-19 induced psychosocial challenges in South African higher education: Experiences of staff and students at two rural universities

Laher, S., Bain, K., Bemath, N., de Andrade, V., \& Hassem, T. (2021). Undergraduate psychology student experiences during COVID-19: Challenges and lessons learnt. South African Journal of Psychology, 1-14. https://doi.org/10.1177/0081246321995095

Leavy, P. (2017). Research design: Quantitative, qualitative, mixed methods, arts-based, and community-based participatory research approaches. New York: The Guilford Press.

Lima, C., Carvalho, P., Lima, I., Nunes, J., \& Saraiva, J. d. (2020). The emotional impact of Coronavirus 2019-nCoV (new Coronavirus disease). Psychiatry Research, 287, 112915. https://doi.org/10.1016/j.psychres.2020.112915

Liu, C. H., Zhang, E., Wong, G. T., Hyun, S., \& Hahm, H. C. (2020). Factors associated with depression, anxiety, and PTSD symptomatology during the COVID-19 pandemic: Clinical implications for U.S. young adult mental health. Psychiatry Research, 290, 113172. https://doi.org/10.1016/j.psychres.2020.113172

Mahase, E. (2020). COVID-19: hoarding and misuse of protective gear is jeopardising the response, WHO warns. BMJ, 368-369. https://doi.org/10.1136/bmj.m869

Makhubela, M. (2021). Suicide and depression in university students: A possible epidemic. South African Journal of Psychology, 51(1), 3-5. https://doi.org/10.1177/0081246321992179

McCorkle, W. (2020). Problematizing Immigration Restrictions duringCOVID-19 in the Social Studies Classroom. Research in Social Sciences and Technology, 5(3), 1-24. https://doi.org/10.46303/ressat.05.03.1

Miller, D., Gilman, R., \& Martens, M. (2008). Wellness promotion in the schools: Enhancing students' mental and physical health. Psychology in the Schools, 45, 5-15. https://doi.org/10.1002/pits.20274

Mncube, V. S., Mutongoza, B. H., \& Olawale, B. E. (2021). Managing higher education institutions in the context of COVID-19 stringency: Experiences of stakeholders at a rural South African university. Perspectives in Education, 39(1), 390-409. https://doi.org/10.18820/2519593X/pie.v39.i1.24

Muhuro, P., \& Kang'ethe, S. M. (2021). Prospects and pitfalls associated with implementing blended learning in rural-based higher education institutions in Southern Africa. Perspectives in Education, 39(1), 427-441. https://doi.org/10.18820/2519593X/pie.v39.i1.26

Ntshwarang, P. N., Malinga, T., \& Losike-Sedimo, N. (2021). eLearning tools at the University of Botswana: Relevance and use under COVID-19 crisis. Higher Education for the Future, 8(1), 142-154. https://doi.org/10.1177/2347631120986281

Patterson, L., Brooke, M., Faulkner, A., \& Pettigrew, A. (2020). COVID-19: Higher Ed Crisis Management. Pilbara: Higher Education Analytics. Retrieved from https://www.pilbaragroup.com/COVID-19-higher-ed-crisis-management/

Pillay, A. L., Thwala, J. D., \& Pillay, I. (2020). Depressive symptoms in first year students at a rural South African university. Journal of Affective Disorders, 265, 579-582. https://doi.org/10.1016/j.jad.2019.11.094

Poalses, J., \& Bezuidenhout, A. (2018). Mental health in higher education: A comparative stress risk assessment at an open distance learning university in South Africa. 
Olawale, B.E. et al. COVID-19 induced psychosocial challenges in South African higher education: Experiences of staff and students at two rural universities

International Review of Research in Open and Distributed Learning, 19(2), 169-191. https://doi.org/10.19173/irrodl.v19i2.3391

Rajkumar, R. P. (2020). COVID-19 and mental health: A review of the existing literature. Asian Journal of Psychiatry, 52, 102066. https://doi.org/10.1016/j.ajp.2020.102066

Rousseau, K.-L., Thompson, S., Pileggi, L.-A., Henry, M., \& Thomas, K. G. (2021). Trends in the prevelance and severity of depressive symptoms among undergraduate students at a South African university, 2016-2019. South African Journal of Psychology, 51(1), 67-80 https://doi.org/10.1177/0081246320977759

Sahu, P. (2020). Closure of universities due to coronavirus disease 2019(COVID-19): Impact on education and mental health of students and academic staff. Cureus, 12(4), e7541. https://doi.org/10.7759/cureus.7541

Shimazu, A., Nakata, A., Nagata, T., Arakawa, Y., Kuroda, S., Inamizu, N., \& Yamamoto, I. (2020). Psychosocial impact of COVID-19 for general workers. Journal of Occupational Health, 1-2. https://doi.org/10.1002/1348-9585.12132

Siu, J. Y. (2008). The SARS-associated stigma of SARS victims in the post-SARS era of Hong Kong. Qualitative Health Research, 729-738. https://doi.org/10.1177/1049732308318372

Taha, S., Matheson, K., Cronin, T., \& Anisman, H. (2014). Intolerance of uncertainty, appraisals, coping, and anxiety: the case of the 2009 H1N1 pandemic. British Journal of Health Psychology, 19(3), 592-605. https://doi.org/10.1111/bjhp.12058

Tang, W., Hu, T., Hu, B., Jin, C., Wang, G., Xie, C., . . Xu, J. (2020). Prevalence and correlates of PTSD and depressive symptoms one month after the outbreak of the COVID-19 epidemic in a sample of home-quarantined Chinese university students. Journal of Affective Disorders, 27(4), 1-7. https://doi.org/10.1016/i.jad.2020.05.009

UNESCO (2020). COVID-19 and higher education: Today and tomorrow. Madrid: UNESCO. van Zyl, P., Joubert, G., Bowen, E., du Plooy, F., Francis, C., Jadhunandan, S., . . Metz, L. (2017). Depression, anxiety, stress and substance abuse in medical students in a 5year curriculum. African Journal of Health Professions Education, 9(2), 67-72.

Verma, S., Mythily, S., Chan, Y., Deslypere, J., Teo, E., \& Chong, S. (2004). Post-SARS psychological morbidity and stigma among general practitioners and traditional Chinese medicine practitioners in Singapore. Annals of Academy of Medicine Singapore, 33(6), 743-748.

Wang, G., Zhang, Y., Zhao, J., Zhang, J., \& Jiang, F. (2020). Mitigate the effects of home confinement on children during the COVID-19 outbreak. Lancet, 395(10228), 945-947. https://doi.org/10.1016/S0140-6736(20)30547-X

Williams, T.K., McIntosh, R.W., \& Russell, W.B. (2021). Equity in distance education during COVID-19. Research in Social Sciences and Technology, 6(1), 1-24. https://doi.org/10.46303/ressat.2021.1

World Health Organization (2020). Mental health and psychosocial considerations during the COVID-19 outbreak. Retrieved from https://www.who.int/docs/defaultsource/coronaviruse/mental-health-considerations 